\title{
Influence of Water Level Change on Deformation and Stability of Retaining Walls with Different Back Materials
}

\author{
Shangyu $\operatorname{Han}^{1, a}$, Xingxing Wei ${ }^{2, b}$, Kun Yang ${ }^{3, c}$ and,Lei Yun ${ }^{4, d}$,Cong Cheng ${ }^{5, e}$ \\ ${ }^{1}$ College of Civil Construction Nanchang Hang Kong University, Jiangxi Nanchang ;Key Laboratory \\ of water transportation engineering of Ministry of education, Chongqing Jiaotong \\ University,Chongqing \\ ${ }^{2,3,4,5}$ College of Civil Construction Nanchang Hang Kong University, Jiangxi Nanchang

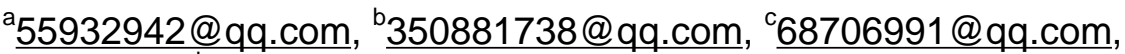 \\ 785410228@qq.com, ${ }^{\mathrm{e}}$ 547104652@qq.com
}

\begin{abstract}
Keywords: water level state; back fill; transverse deformation; vertical deformation; stability Abstract. The deformation and stability of retaining wall are greatly affected by the variation of backfill and the water level of the back wall. In this paper, the deformation and stability of retaining wall with different wall materials are analyzed by finite element simulation analysis. The results show that the horizontal displacement is the biggest when the soil is clay, and the vertical displacement is the largest when the soil is sandy soil, and the horizontal displacement is much larger than that of vertical The safety factor of the retaining wall is influenced by the soil property, and the coefficient of safety of the cohesive soil> the safety coefficient of the silt> the safety coefficient of the sandy soil.
\end{abstract}

\section{Introduction}

Retaining wall deformation and stability are often the focus of retaining wall engineering quality control and difficult. Different types of wall backfill will not only correspond to different wall back earth pressure, but also will show different transverse deformation and vertical deformation, but when the water level changes, there will be different seepage characteristics.

At present, there are some researches on deformation and seepage stability of retaining wall.For example,Ping Wang and others[1] used the reliability theory to analyze and calculate the failure probability of retaining wall. It is considered that the groundwater level and soil parameters are taken as stochastic Qingwei Zhang[2] simulated and analyzed the deformation and stability of soil and surrounding structure around the foundation pit under unsteady seepage conditions. In the paper, the deformation and stability of the retaining wall are analyzed. Junjun Wei and others [3] presented the calculation formulas for judging and analyzing the stability of foundation pit considering seepage. Yeshu Xu, Shuilong Shen and others[4] analyzed the finite element simulation and found that the groundwater level The depth and settlement will increase with the depth of the retaining wall and retaining width of the increase; Yuqi Li, Kang Xie[5] analysis of the role of the seepage on the envelope of water pressure, earth pressure and lateral pressure Affect the situation.

The results show that the existing research results have positive significance for revealing the performance of earth retaining structure. However, the research results can not compare the deformation performance and stability of different fillers under different water level. It is difficult to reveal the variation of water level The deformation and stability of different types of backfill materials were studied.

\section{Finite element model}

\section{Model diagram}

A excavation area of $22378.5 \mathrm{~m}^{2}$, excavation depth of $5 \mathrm{~m}$, using cement mixing pile + bolt support. According to the site survey found that the groundwater level is located below the ground $2.5 \mathrm{~m}, 0-7 \mathrm{~m}$ below the ground sandy soil, $7 \mathrm{~m}$ below siltstone.

Based on the above engineering background to establish finite element simulation analysis model 
is shown in Fig.1.

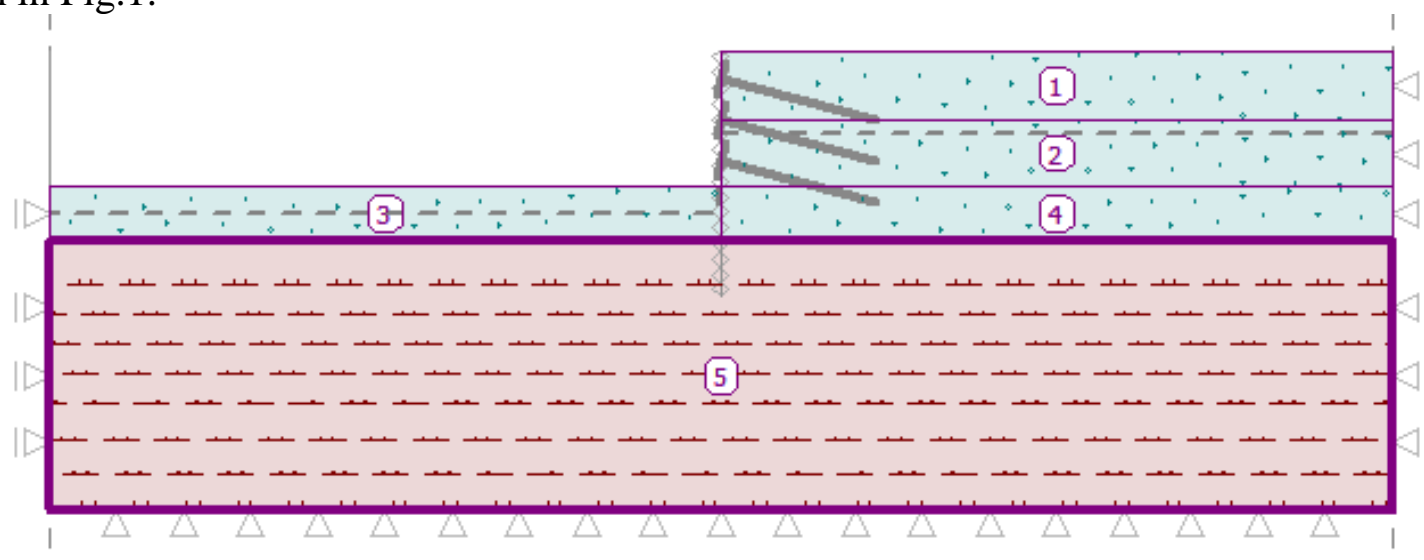

Fig.1 Schematic diagram of finite element simulation analysis model

\section{Determination of model parameters}

According to design and construction data, cement mixing pile length $7 \mathrm{~m}$, pile diameter $1.2 \mathrm{~m}$. Set up before and after the retaining wall water wells. The physical and mechanical parameters of the soil layers after retaining wall are shown in Table 1 . The natural gravity of siltstone is $23 \mathrm{kN} / \mathrm{m}^{3}$.

Table 1 Physical and mechanical parameters of model sandy soil

\begin{tabular}{|c|c|c|c|c|}
\hline Soil typel & $\begin{array}{c}\text { Natural } \\
\text { severe } \\
\left(\mathrm{kN} / \mathrm{m}^{3}\right)\end{array}$ & $\begin{array}{c}\text { Internal } \\
\text { friction angle } \\
\left(0^{\circ}\right.\end{array}$ & $\begin{array}{c}\text { Cohesion } \\
(\mathrm{kPa})\end{array}$ & $\begin{array}{c}\text { Elastic } \\
\text { Modulus } \\
(\mathrm{MPa})\end{array}$ \\
\hline Unsaturated sand & 20 & 41 & 5 & 80 \\
\hline Saturated sand & 25 & 35 & 2 & 65 \\
\hline
\end{tabular}

In order to make the structure more stable, bolts are added to the structure. The upper and lower positions of the bolts are located $1 \mathrm{~m}$ away from the top of the wall, $2.5 \mathrm{~m}$ away from the top of the wall and $4 \mathrm{~m}$ away from the top of the wall. The anchor parameters are shown in Table 2.

Table 2 Anchor Parameters

\begin{tabular}{|c|c|c|c|c|}
\hline Length (m) & Diameter (mm) & $\begin{array}{c}\text { Inclination } \\
(0)\end{array}$ & $\begin{array}{c}\text { Anchoring force } \\
(\mathrm{kN})\end{array}$ & $\begin{array}{c}\text { Horizontal } \\
\text { Spacing of } \\
\text { Anchors (m) }\end{array}$ \\
\hline 6 & 25 & 15 & 185 & 1 \\
\hline
\end{tabular}

The soil layer with great influence on the stability and deformation of the retaining wall is sand layer. The characteristic points are located at the top of the retaining wall, $2.5 \mathrm{~m}$ from the top of the wall, $7 \mathrm{~m}$ from the wall, $7 \mathrm{~m}$ from the wall $\mathrm{Wall}$ at the end. Considering the need of comparative analysis, the sand layers in the model are replaced by cohesive soil layer and silt soil layer respectively. The physical parameters of clayey soil and silty soil are shown in Table 3 and Table 4. 
Table 3 Physico-mechanical parameters of cohesive soils

\begin{tabular}{|c|c|c|c|c|}
\hline Soil typel & $\begin{array}{c}\text { Natural } \\
\text { severe } \\
\left(\mathrm{kN} / \mathrm{m}^{3}\right)\end{array}$ & $\begin{array}{c}\text { Internal } \\
\text { friction angle } \\
(\circ)\end{array}$ & $\begin{array}{c}\text { Cohesion } \\
(\mathrm{kPa})\end{array}$ & $\begin{array}{c}\text { Elastic } \\
\text { Modulus } \\
(\mathrm{MPa})\end{array}$ \\
\hline Unsaturated Cohesive soil & 21 & 21 & 16 & 6 \\
\hline Saturated Cohesive soil & 23 & 17 & 10 & 3 \\
\hline
\end{tabular}

Table 4 Powder physical and mechanical parameters

\begin{tabular}{|c|c|c|c|c|}
\hline Soil typel & $\begin{array}{c}\text { Natural } \\
\text { severe } \\
\left(\mathrm{kN} / \mathrm{m}^{3}\right)\end{array}$ & $\begin{array}{c}\text { Internal } \\
\text { friction angle } \\
\left(0^{\circ}\right.\end{array}$ & $\begin{array}{c}\text { Cohesion } \\
(\mathrm{kPa})\end{array}$ & $\begin{array}{c}\text { Elastic } \\
\text { Modulus } \\
(\mathrm{MPa})\end{array}$ \\
\hline Unsaturated silt & 18 & 29 & 14 & 8 \\
\hline Saturated silt & 22 & 25 & 8 & 5 \\
\hline
\end{tabular}

\section{Influence of Water Level Change on Horizontal Displacement of Retaining Wall}

Based on the above model, the horizontal displacements of the backfill of different types of retaining walls are simulated and analyzed when the water level gradually rises from the bottom of the pit to the top of the retaining wall. The top of the retaining wall is $2.5 \mathrm{~m}$ away from the top of the wall, The horizontal displacement of the bottom of the pit, $7 \mathrm{~m}$ away from the top of the wall and the bottom of the retaining wall is shown in Fig.2.

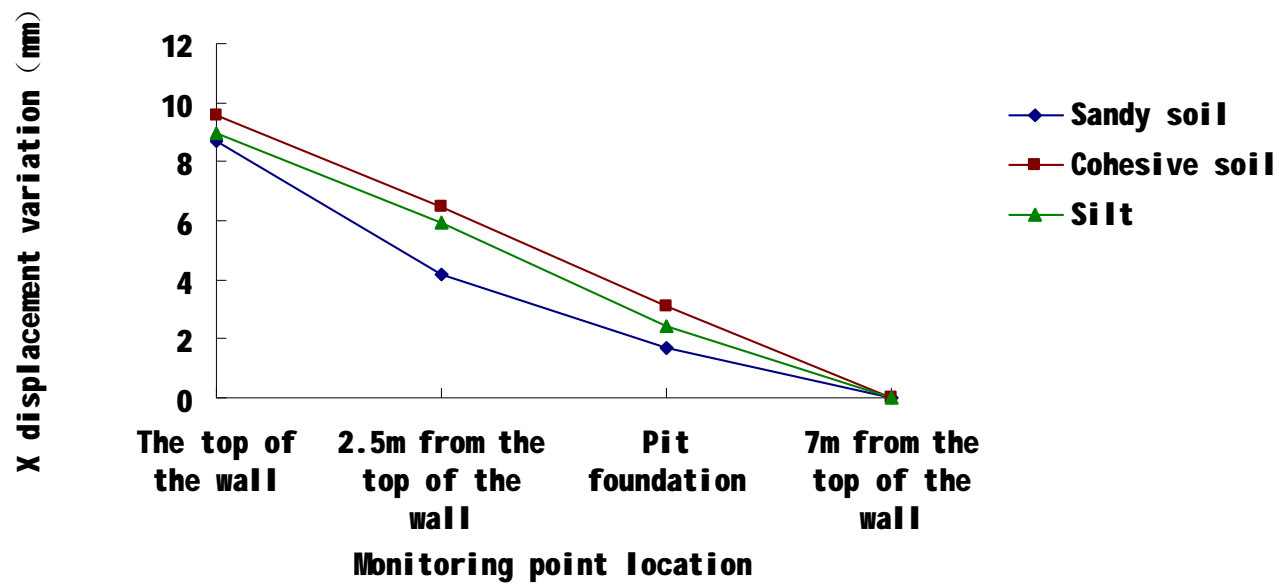

Fig.2 Horizontal displacement variation of different soil properties

Figure 2 illustrates that the water level from the pit pit up to the wall of the process, the wall will appear away from the back wall of the horizontal displacement of the fill, and the wall of the horizontal displacement variation from the top of the wall to the bottom of the linear approximation . At the same time, from the relationship between the soil and the horizontal displacement, the horizontal displacement of the retaining wall structure from the bottom to the top of the wall is in the order of cohesive soil > silt > Sandy soil.

\section{Influence of Water Level Change on Vertical Displacement of Retaining Wall}

Based on the above-mentioned model, the vertical displacement of backfill of different types of 
retaining wall is simulated and analyzed when the water level gradually descends from the top of the pit to the bottom of the pit. The top of the retaining wall is $2.5 \mathrm{~m}$, The vertical displacement of the bottom of the pit, $7 \mathrm{~m}$ away from the top of the wall and the bottom of the retaining wall is shown in Fig.3.

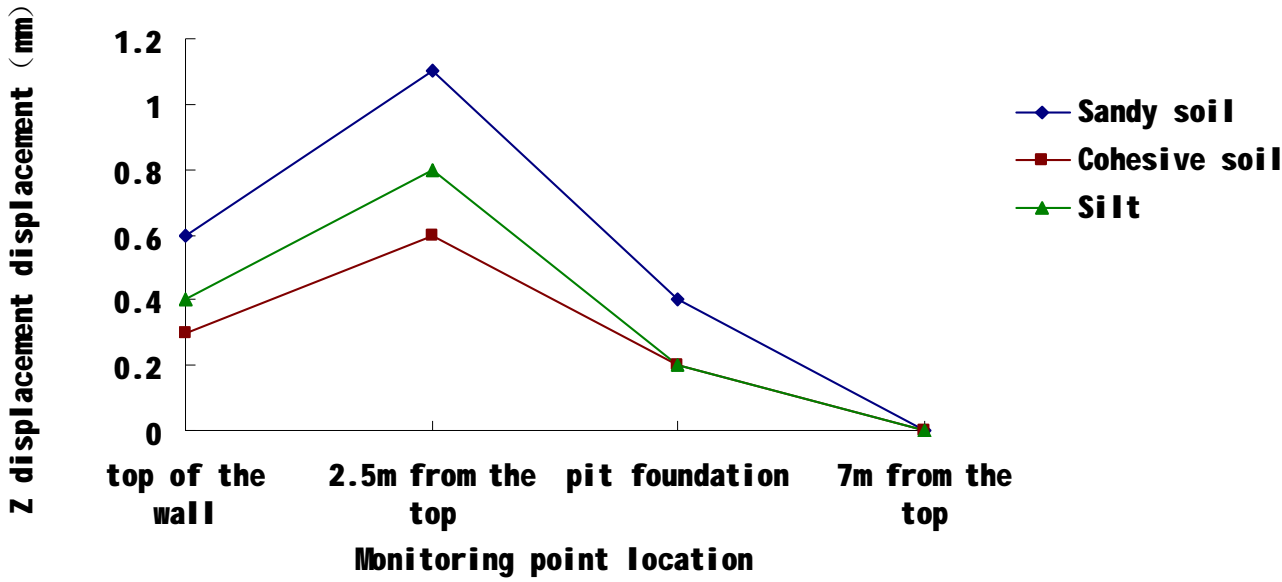

Fig.3 Variation of vertical displacement of different soil properties

It can be seen from Figure 3, the water level from the pit pit down to the pit pit, the wall will appear downward vertical displacement, and retaining wall at $2.5 \mathrm{~m}$ away from the top of the vertical displacement of the maximum amount of change, Followed by the top of the wall of the vertical displacement of the displacement; but the maximum vertical displacement of only $1.1 \mathrm{~mm}$. At the same time, from the relationship between soil and horizontal displacement, in the process of water level descending from the top of the wall to the bottom of the pit, the change of the vertical displacement of the retaining wall structure from large to small corresponds to sandy soil> Silt> cohesive soil.

Comparing Fig. 2 and Fig. 3, it can be seen that the horizontal displacement change caused by the lateral water level change of the retaining wall is much greater than the vertical displacement.

\section{The influence of the change of water level on the stability of retaining wall}

Using the above model, the water level from the pit pit gradually rising to the wall of the retaining wall in the process of different water levels corresponding to the different types of retaining wall backfill security state simulation analysis, the water level is located on the top of the retaining wall, Wall top $2.5 \mathrm{~m}$, pit base, from the top of the wall $7 \mathrm{~m}$, retaining wall wall of different types of wall backfill wall safety factor changes shown in Figure 4.

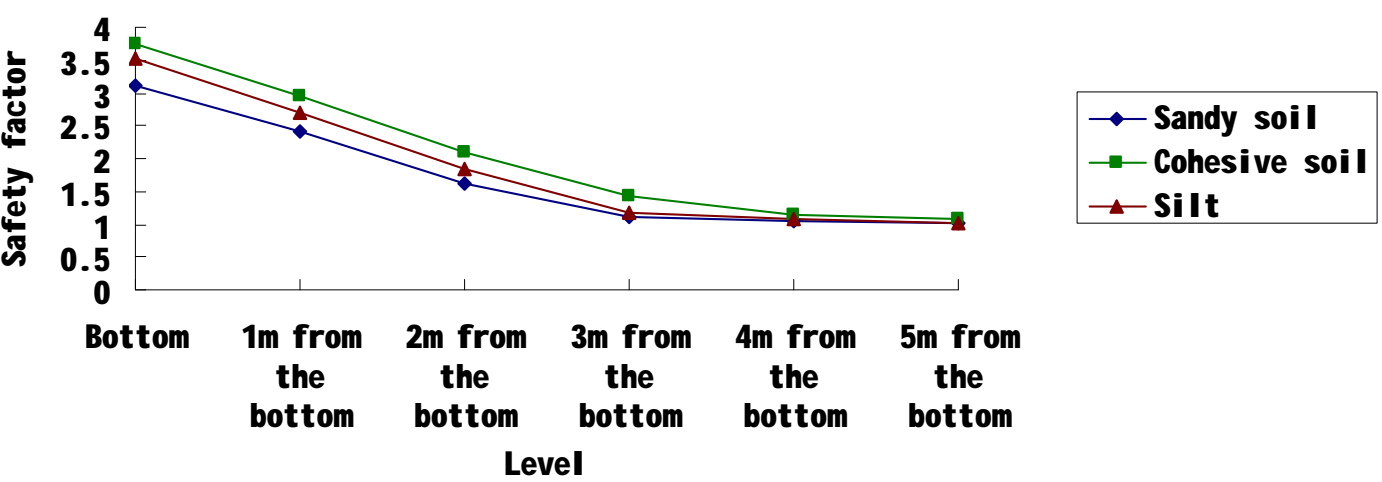

Fig.4 The safety factor of retaining wall with different backfill under different water leve 
From Fig.5, it can be seen that with the rise of water level, the safety factor of sandy soil, cohesive soil and silt is decreased by curve, and when the water level of the wall is close to the wall bottom, the safety coefficient The safety factor of the retaining wall is bigger than that of the retaining wall; the safety coefficient of the cohesive soil> the safety coefficient of the silty soil > the safety coefficient of the sandy soil from the view of the safety coefficient.

\section{Conclusions}

(1) The horizontal displacement of the retaining wall decreases linearly from the top of the wall to the bottom of the wall, and the horizontal displacement of the retaining wall is the largest when the water level rises from the pit bottom to the wall top. The change of horizontal displacement is the smallest when the soil is sandy soil.

(2) In the process of the water level descending from the top of the wall to the bottom of the pit, the vertical displacement of the retaining wall is in the order of sandy soil $>$ silt $>$ cohesive soil, and the water level of the retaining wall The amount of change in horizontal displacement caused by the change is much greater than the change in vertical displacement.

(3) With the rise of water level, the safety factor of sandy soil, cohesive soil and silty soil is decreased with the increase of water level, the safety coefficient of retaining wall is bigger, the safety of cohesive soil coefficient > silt safety factor $>$ sand soil safety factor.

\section{Acknowledgements}

Fund Project: Chongqing Jiaotong University National Inland Waterway Regulation Engineering Technology Research Center and Key Laboratory of Water Conservancy and Water Transport Engineering Ministry of Education Key Laboratory Open Fund (SLK2014A02)

First Author: Shangyu Han, Male, in August 1979, Ph.D., lecturer, mainly engaged in geotechnical engineering teaching and research work. Email: 55932942@qq.com

Corresponding author: Xingxing Wei , Male, in August 1990, graduate students, mainly engaged in the research work of geotechnical engineering. Email: 350881738@qq.com

\section{References}

[1] Ping Wang,Dongsheng Liu, et al.Stability analysis of retaining wall under groundwater (In Chinese)[J].2001,21 (5): 475-481.

[2] Qingwei Zhang.Stability analysis of foundation pit supporting structure under unsteady seepage (In Chinese)[D] .Zhengzhou: Zhengzhou University, 2007.

[3] Wei Junjun,Liwei Zhang, et al. Seepage stability analysis of foundation pit (In Chinese)[J]. Journal of Water Resources and Architectural Engineering, 2012,10 (3): 79-82.

[4] YeShuang $\mathrm{Xu}$, ShuiLong Shen,Lei Ma.Blocking Effect of Underground Structures on Groundwater Seepage (In Chinese)[J].Journal of Zhejiang University (Engineering Science),2010, 44(10): 1902-1906.

[5] Yuqi Li,Kanghe Xie.Stability analysis of foundation pit retaining structure considering seepage effect (In Chinese)[J] .Acta Scientiae Circumstantiae, 2005, 21 (4): 440-444. 